\title{
IMPLEMENTASI APLIKASI PEMBELAJARAN UNTUK ANAK BERBASIS ANDROID
}

\author{
Sam'ani'), Sutami' $^{2)}$, M. Haris Qamaruzzaman ${ }^{3)}$. \\ 1, 2 \& 3) Ilmu Komputer, Fakultas Teknik Universitas Muhammadiyah Palangkaraya \\ sam.umpalangkaraya@gmail.com.
}

\begin{abstract}
To improve the quality of learning required the use of information technology in learning media. The use of information technology and media in learning can form a learning atmosphere in which students can actively participate. Currently, children are increasingly familiar and attached to the name of a smartphone or tablet. At present, when the world is entering the era of the industrial revolution 4.0. Or the fourth world industrial revolution where technology has become the basis in human life the use of information and communication technology for learning must begin at the Early Childhood Education level (PAUD) to be more interesting and interactive and increase children's interest and curiosity in what taught. The method of applying science and technology is carried out with mobile technology which is very popular at the moment, the Android-based children's learning application as an effort to increase knowledge and understanding and increase the learning interest of children in grades 2, 3 and 4 of Bereng Kajang I. The purpose of the implementation of this program is to increase knowledge and understanding as well as increase learning interest of students in grades 2, 3 and 4 of SDN Bereng Kajang I about various things including letters, numbers, colors, vegetables, animals, fruits, jobs and vehicles. Both in Indonesian and English pronunciation through the implementation/dissemination of learning applications for children based on Android.
\end{abstract}

Keywords: Learning Application, Children, Android, Implementation

\begin{abstract}
Abstrak
Dalam upaya peningkatan kualitas pembelajaran diperlukan penggunaan teknologi informasi dalam media pembelajaran. Penggunaan teknologi informasi dan media dalam pembelajaran dapat membentuk atmosfer pembelajaran di mana siswa dapat aktif berpartisipasi. Saat ini, anak-anak sudah semakin familiar dan lekat dengan yang namanya smartphone ataupun tablet. Saat ini ketika dunia tengah memasuki era revolusi industri 4.0. atau revolusi industri dunia ke-empat dimana teknologi telah menjadi basis dalam kehidupan manusia pemanfaatan teknologi informasi dan komunikasi untuk pembelajaran harus dimulai dari tingkat Pendidikan Anak Usia Dini (PAUD) agar dapat semakin menarik dan interaktif serta menambah rasa minat dan keingintahuan anak terhadap apa yang diajarkan. Metode penerapan ipteks yang dilakukan adalah dengan teknologi mobile yang sangat populer saat ini yaitu aplikasi pembelajaran anak berbasis android sebagai upaya peningkatan pengetahuan dan pemahaman serta menambah minat belajar anak siswa kelas 2, 3 dan 4 SDN Bereng Kajang I. Tujuan dari pelaksanaan program ini adalah untuk meningkatkan pengetahuan dan pemahaman serta menambah minat belajar anak siswa kelas 2, 3 dan 4 SDN Bereng Kajang I tentang berbagai hal diantaranya mengenai huruf, angka, warna, sayuran, binatang, buah, pekerjaan dan kendaraan. Baik dalam pengucapan Bahasa Indonesia ataupun Bahasa Inggris melalui implementasi/sosialisasi aplikasi pembelajaran untuk anak berbasis Android.
\end{abstract}

Kata Kunci : Aplikasi pembelajaran, Anak-anak, Android, Implementasi

\section{PENDAHULUAN}

Proses pembelajaran pada hakikatnya adalah proses interaksi dua arah yang melibatkan komunikasi antara guru dengan siswa. Proses komunikasi ini terdiri atas kegiatan penyampaian pesan (materi pembelajaran) antara pengirim (guru) kepada penerima (siswa). Penyampaian pesan membutuhkan penggunaan media yang tepat agar pembelajaran dapat berjalan dengan efektif dan efisien. Oleh karena itu, media pembelajaran menjadi cukup penting karena tanpa media maka komunikasi tidak akan terjadi dan proses pembelajaran tidak akan berlangsung optimal (Nugroho et al., 2014). 
Teknologi sangat diperlukan dalam pembuatan media pembelajaran. Penggunaan media dapat meningkatkan keaktifan siswa (Yuntoto, 2015). Terlebih lagi bagi anak-anak usia 6-8 tahun. Anak pada usia ini berada pada periode intelektual yaitu suatu periode dimana pengetahuan anak akan bertambah pesat seiring dengan bertambahnya usia, keterampilan yang dikuasaipun semakin beragam. Minat anak pada periode ini terutama terfokus pada segala sesuatu yang bersifat dinamis bergerak/multimedia.

Teknologi di era modernisasi ini semakin berkembang pesat, berbagai macam teknologi tidak terhitung jumlahnya (Sam'ani, 2018). Salah satu teknologi yang sangat popular adalah smartphone/gadget. Smartphone ini dapat ditemui dimanapun, baik pada orang dewasa maupun anakanak. Anak-anak kini telah menjadi konsumen aktif dimana banyak produkproduk smartphone yang menjadikan anakanak sebagai target pasar mereka (Carolina, 2016).

Smartphone dapat membantu proses pembelajaran. Smartphone diharapkan dapat memecahkan masalah akses terhadap sumber-sumber belajar pada masa mendatang. Apalagi ditunjang dengan harga smartphone yang semakin hari semakin murah dan dapat terjangkau oleh semua kalangan masyarakat. Teknologi pada Smarphone berkembang sangat pesat. Hal ini ditandai dengan munculnya beberapa sistem operasi mobile seperti OS, Android, iOS dan Windows.

Sistem operasi mobile yang paling populer saat ini adalah android sDengan menggunakan smartphone berbasis android yang berisikan aplikasi/perangkat lunak pembelajaran multimedia untuk anak usia antara $6-8$ tahun berbasis android yang akan diimplementasika/disosialisasikan pada anak-anak Sekolah Dasar Negeri Bereng Kajang I yang berlokasi di jalan Trans Kalimantan Km 34 terutama siswa kelas 2, 3 dan 4, diharapkan dapat dijadikan salah satu cara alternatif dalam upaya untuk meningkatkan pemahaman dan pengetahuan serta minat belajar anak-anak pada SDN tersebut tentang berbagai hal diantaranya mengenal huruf, angka, warna, sayuran, binatang, buah, pekerjaan dan kendaraan. Baik dalam pengucapan Bahasa Indonesia ataupun Bahasa Inggris.

\section{METODE}

Kegiatan Pengabdian masyarakat ini dilaksanakan oleh Universitas Muhammadiyah Palangkaraya melalui program studi Ilmu Komputer (Fakultas Teknik). Pelaksanaan kegiatan ini akan dilaksanakan secara berkala tiap tahun terutama karena akan ada pengembangkan terus untuk aplikasi berbasis Android yang digunakan dan pada tahun 2019 ini akan diadakan pada bulan Agustus Sekolah Dasar Negeri Bereng Kajang I yang berlokasi di jalan Trans Kalimantan Km 34 Tumbang Nusa, Kabupaten Pulang Pisau. Format Kegiatan Pengabdian Pada Masyarakat ini berupa Implementasi Aplikasi Pembelajaran Anak Android.

\section{HASIL DAN PEMBAHASAN}

Kegiatan P2M ini bertujuan terutama dalam upaya untuk meningkatkan pengetahuan dan pemahaman serta minat belajar anak melalui implementasi dan sosialisasi aplikasi pembelajaran untuk anak berbasis Android khususnya bagi siswa kelas 2, 3 dan 4 SDN Bereng Kajang I yang berlokasi di jalan Trans Kalimantan Km 34 Tumbang Nusa, Kabupaten Pulang Pisau.

Kegiatan P2M ini dilaksanakan pada minggu ke 2 bulan Agustus 2019 dimulai pukul 08.00 WIB sampai selesai. Adapun Narasumber dalam kegiatan ini adalah dosen program studi Ilmu Komputer Fakultas Teknik Universitas Muhammadiyah Palangkaraya yang akan mendemontrasikan penggunaan aplikasi pada smartphone Android. Kegiatan ini dimulai dengan praktek secara langsung penggunaan aplikasi pada smartphone Android dan tanya jawab yang disertai pembagian door prize bagi 
para siswa yang ikut bisa menjawab pertanyaan dengan benar.

Program Kegiatan ini menghasilkan beberapa hal, yaitu :

1. Peningkatan pengetahuan dan pemahaman para peserta kegiatan terutama anak-anak siswa kelas 2, 3 dan 4 SDN Bereng Kajang I Tumbang Nusa, Kabupaten Pulang Pisau.

2. Mulai dimanfaatkannya berbagai fasilitas kecanggihan smartphone berbasis Android terutama untuk aplikasi-aplikasi pembelajaran dan pendidikan bagi tenaga pendidik/guruguru.

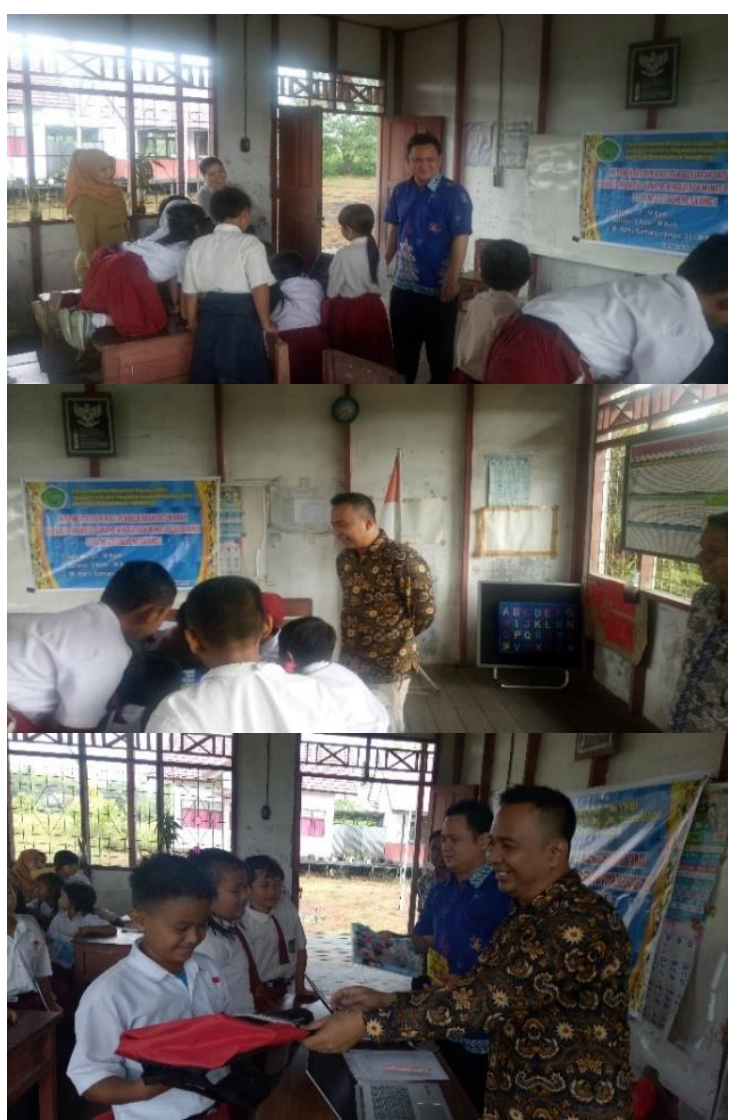

Gambar 1. Kegiatan implementasi aplikasi pembelajaran berbasis android

screenshoot tampilan aplikasi android yang diimplementasikan dapat dilihat pada gambar 2, gambar 3, gambar 4, gambar 5, gambar 6, dan gambar 7 .
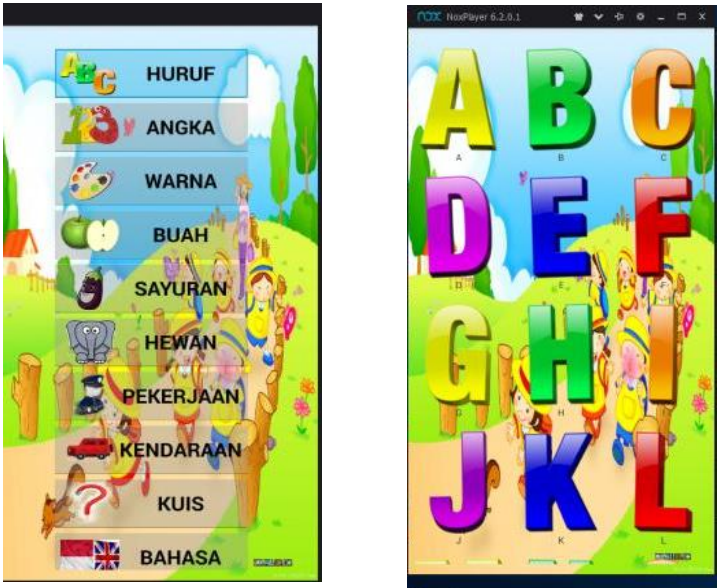

Gambar 2. Menu Utama dan Menu huruf
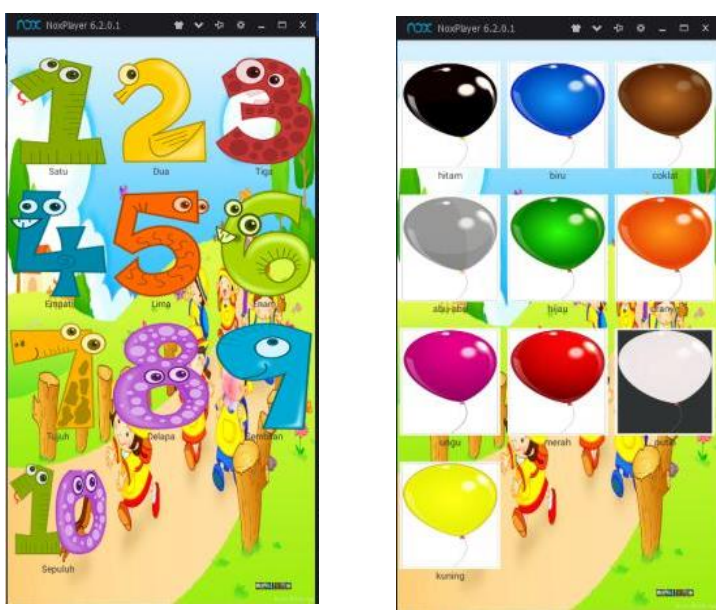

Gambar 3. Menu angka dan Menu Warna
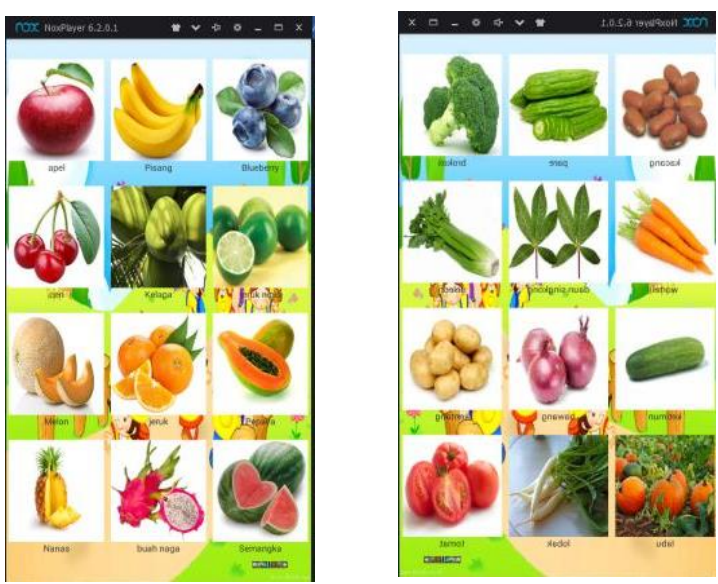

Gambar 4. Menu Buah dan Menu Sayuran 

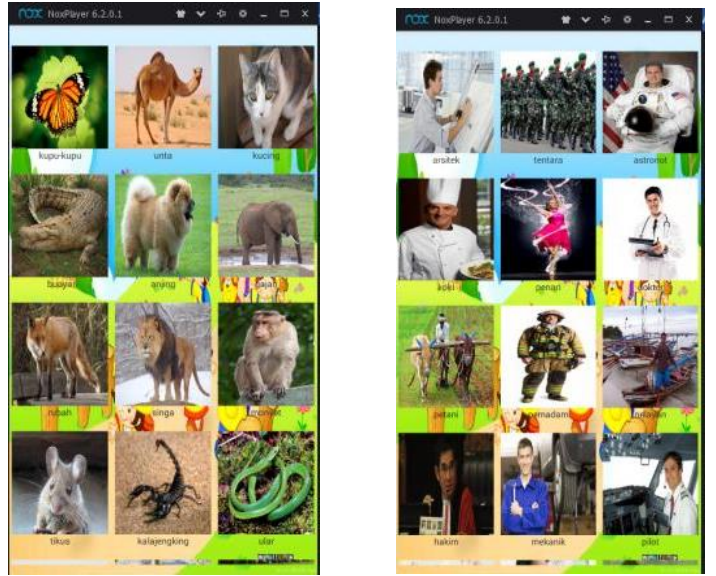

Gambar 5. Menu Hewan dan Pekerjaan
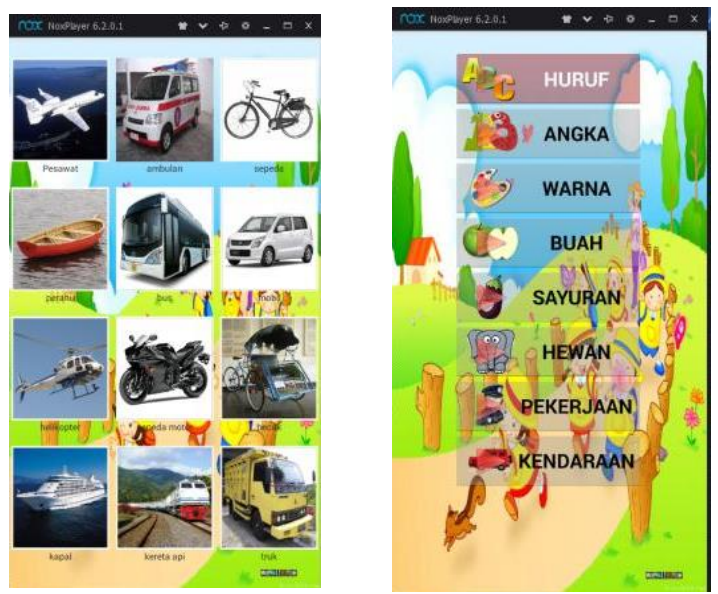

Gambar 6. Menu Kendaraan dan Kuis
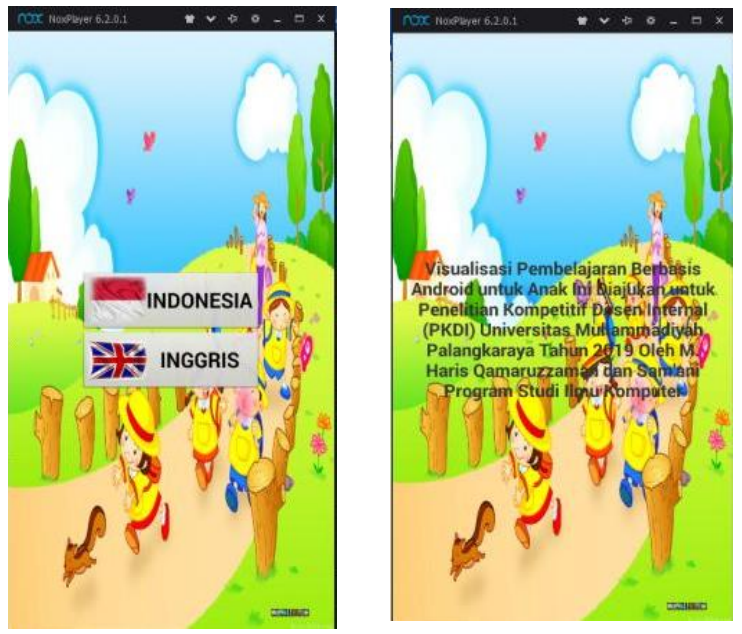

Gambar 7. Menu Bahasa dan Tentang

\section{KESIMPULAN}

Kegiatan P2M ini telah berhasil meningkatkan pengetahuan dan pemahaman mengenal huruf, angka, warna, sayuran, binatang, buah, pekerjaan dan kendaraan. Hal ini berdasarkan dengan mudahnya para siswa menjawab berbagai pertanyaan yang diajukan selama sesi tanya jawab.

Para guru juga antusias untuk minta diinstalkan pada smartphone masingmasing dan diajarkan penggunaan aplikasi yang digunakan pada kegiatan ini.

\section{UCAPAN TERIMA KASIH}

Ucapan terima kasih kami sampaikan kepada pihak-pihak yang telah berpartisipasi pada kegiatan pengabdian pada masyarakat ini, yaitu : Universitas Muhammadiyah Palangkaraya melalui Lembaga Penelitian dan Pengabdian Kepada Masyarakat (LP2M) yang telah mendanai program ini, Kepala Sekolah dan Guru serta para siswa kelas 2, 3 dan 4 SDN Bereng Kajang I Tumbang Nusa, Kabupaten Pulang Pisau yang telah bersedia menjadi peserta kegiatan ini hingga selesai.

\section{DAFTAR PUSTAKA}

Bernardianto, R. B., Sam'ani and Qamaruzzaman, M. H. (2018) Meningkatan Kesadaran Hukum Berlalu Lintas Dan Sosialisasi Aplikasi Rambu Lalu Lintas Berbasis Android. Palangka Raya: Universitas Muhammadiyah Palangkaraya.

Carolina, R. (2016) Pembangunan Aplikasi Game Edukasi Bermain Dan Belajar Pada Anak Usia Dini Berbasis Android. Kediri: Universitas Nusantara Persatuan Guru Republik Inodonesia Kediri.

Nugroho, M. A. et al. (2014) Pelatihan Pembuatan Media Pembelajaran Berbasis Web Blog Dan Aplikasi Android Bagi Guru SMK. Yogyalarta: Universitas Negeri Yogyakarta.

Sam'ani (2018) 'Rancang Bangun Aplikasi Pengawasan Dan Pengendalian 
Sam'ani, Dkk. Implementasi Aplikasi Pembelajaran Untuk Anak Berbasis Android

Komputer Laboratorium

Multimedia STMIK Palangkaraya',

Jurnal Sains Komputer dan

Teknologi Informasi, 1(1), pp. 33-

38. doi: 10.33084/jsakti.v1i1.548.

Yuntoto, S. (2015) Pengembangan Aplikasi

Android Sebagai Media

Pembelajaran Kompetensi

Pengoperasian Sistem Pengendali

Elektronik Pada Siswa Kelas XI

SMKN 2 Pengasih. Yogyakarta:

Universitas Negeri Yogyakarta. 